(C) Elsevier Sequoia S.A., Lausanne - Printed in The Netherlands

Short communication

\title{
DYNAMIC AGEING OF AN OXYGEN-CONTAINING MONOLAYER AT PLATINUM AND GOLD ELECTRODES IN AQUEOUS ACID SOLUTIONS
}

\author{
N.R. de TACCONI, J.O. ZERBINO, M.E. FOLQUER and A.J. ARVIA
}

Instituto de Investigaciones Fisicoquímicas Teóricas y Aplicadas, División Electroquímica, Universidad Nacional, La Plata (Argentina)

(Received 7 th January 1977)

It is already well established that oxygen-containing species electrochemically formed in the monolayer range on $\mathrm{Pt}$ and Au electrodes in acid electrolytes undergo ageing processes which are easily evidenced by a potential shift of the corresponding electroreduction current peak observed under a cathodic linear potential sweep [1-3]. During the ageing process the oxygen containing surface species undergoes a change into another one involving a more stable configuration but without any detectable change of the oxygen/surface metal atomic ratio. The ageing process takes place simultaneously with the electrosorption of oxygen [4] and its contribution can be reasonably controlled during the electrodesorption process as is the case, for instance, when the surface species is allowed to stay under open circuit for a certain time after its electrochemical formation.

If the ageing process corresponds to a reaccommodation of the surface structures acquiring more stable configurations, it should, in principle, also be produced under any kind of perturbation able to promote a shift of the first layers of metal atoms from their equilibrium positions. One way to observe this effect is by means of a sequence of symmetrical triangular potential sweeps as illustrated in Fig. 1. It consists of a first triangular sweep (I) at $v_{\mathrm{a}}=v_{\mathrm{c}}$ starting from $E_{\mathrm{i}}$ up to $E_{\lambda}$ and vice versa, followed by a fast repetitive triangular potential

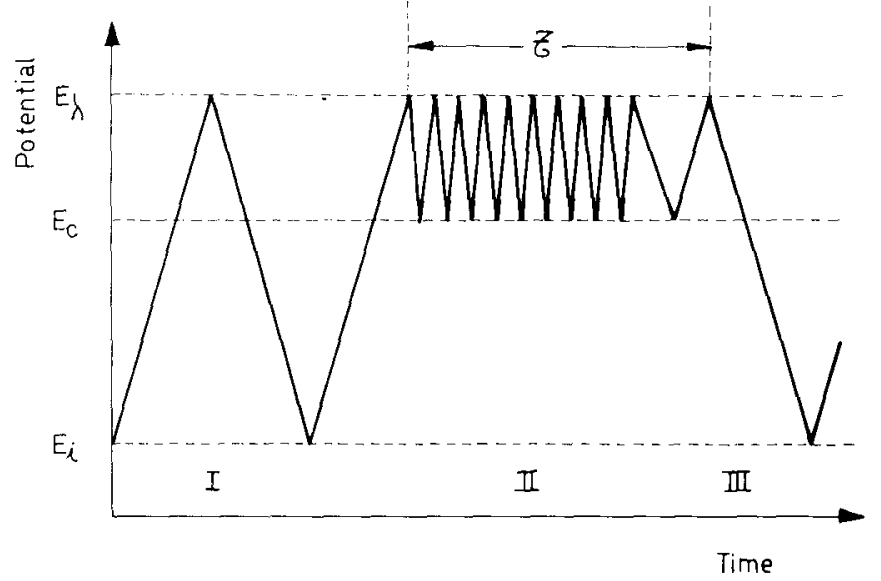

Fig. 1. Sequence of potential perturbations. 


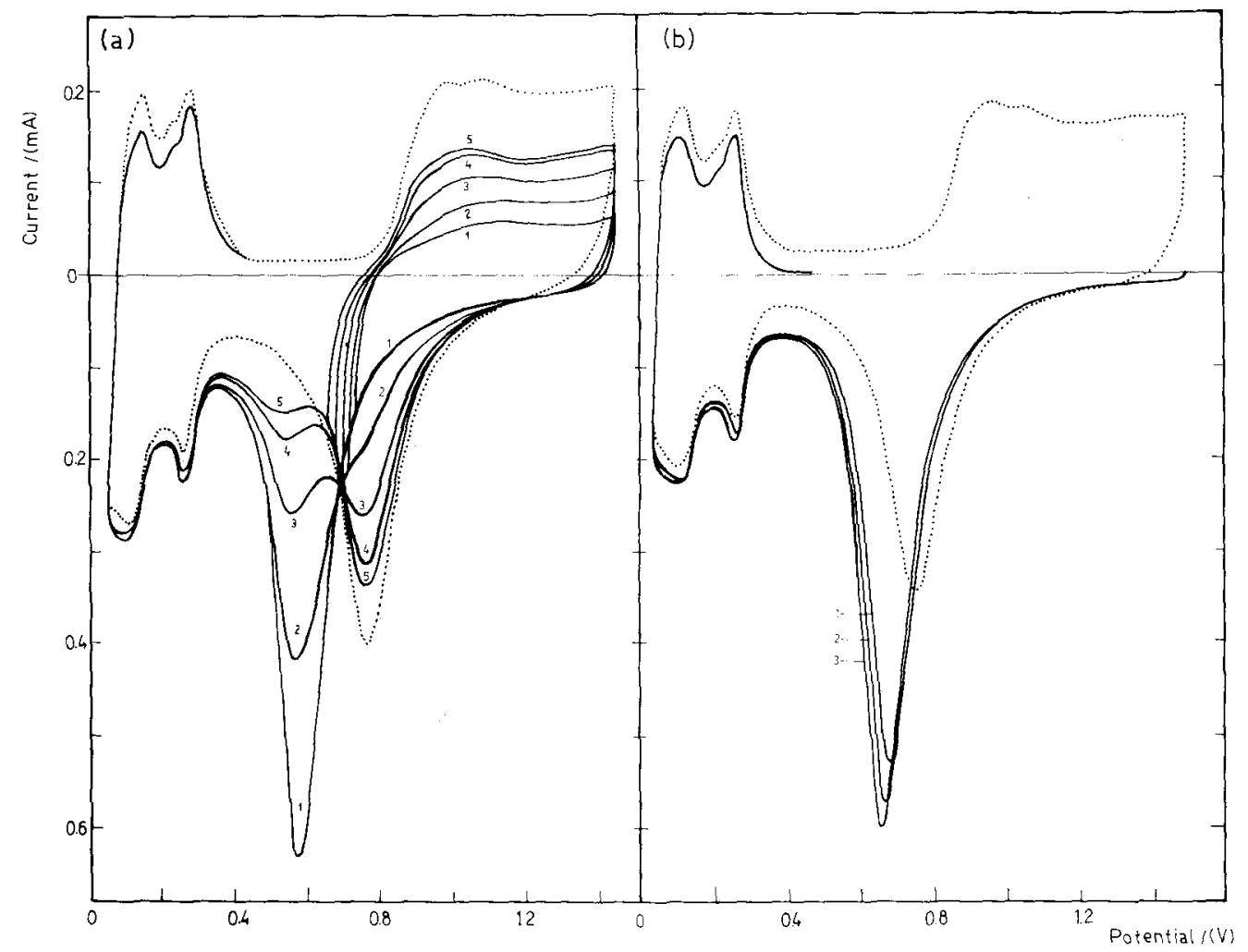

Fig. 2. $E / I$ displays obtained with the $\mathrm{Pt} / 0.1 \mathrm{M} \mathrm{H}_{2} \mathrm{SO}_{4}$ system at $25^{\circ} \mathrm{C}$. Electrode area 0.2 $\mathrm{cm}^{2}$. (a) $E / I$ displays resulting with the potential perturbations as indicated in Fig. 1. $E_{\mathrm{i}}$ $=0.05 \mathrm{~V} ; E_{\lambda}=1.45 ; v_{\mathrm{a}}=v_{\mathrm{c}}=0.4 \mathrm{~V}^{-1} \mathrm{~s} ; v_{\mathrm{a}}^{\prime}=v_{\mathrm{c}}^{\prime}=4 \mathrm{~V}^{-1} \mathrm{~s} ; \tau=3 \mathrm{~min} ; E_{\mathrm{c}}=0.74 \mathrm{~V}$ (curve 1), $0.72 \mathrm{~V}$ (curve 2), $0.70 \mathrm{~V}$ (curve 3 ), $0.68 \mathrm{~V}$ (curve 4), and $0.66 \mathrm{~V}$ (curve 5). (b) $E / I$ displays obtained after different potentiostatting times at $E_{\lambda} \cdot E_{i}=0.05 \mathrm{~V} ; E_{\lambda}=1.49 \mathrm{~V} ; v_{\mathrm{a}}=v_{\mathrm{c}}=0.4$ $\mathrm{V}^{-1} \mathrm{~s} ; t=3 \mathrm{~min}$ (curve 1), $9 \mathrm{~min}$ (curve 2) and $90 \mathrm{~min}$ (curve 3 ). (. . . .) Steady $E / I$ displays of the conventional symmetric triangular potential sweeps obtained before perturbation stage II.

perturbation (II) during time $\tau$, at $v_{\mathrm{a}}^{\prime}=v_{\mathrm{c}}^{\prime}>>v_{\mathrm{a}}=v_{\mathrm{c}}$ within a potential range $\left(E_{\lambda}-E_{\mathrm{c}}\right)<\left(E_{\lambda}-E_{\mathrm{i}}\right)$ and finally a single last triangular potential sweep (III) at $v_{\mathrm{a}}=v_{\mathrm{c}}$ to evidence the energetic changes occurred at the surface compound. Experiments made with $\mathrm{Pt} / 0.1 \mathrm{MH}_{2} \mathrm{SO}_{4}$ (Fig. 2a), $\mathrm{Pt} / 0.15 \mathrm{MClO}_{4}$ and $\mathrm{Pt} / 3 \mathrm{M}$ $\mathrm{H}_{3} \mathrm{PO}_{4}$ interfaces show a clear change between the cathodic $E / I$ profile obtained before and after the fast repetitive perturbation (II). Thus, when the triangular potential excursion (I) covers from 0.06 to $1.45 \mathrm{~V}$ (vs. NHE), the $E / I$ display exhibits during the anodic scan the current peaks related to the hydrogen adatom electrodesorption at a low potential region and the oxygen monolayer electrosorption at the higher potentials, while during the cathodic scan one observes only a single relatively wide oxygen electrodesorption current peak at high anodic potentials together with the hydrogen adatom electrosorption in the potential region preceding the hydrogen evolution. This situation changes quite markedly when the potential at the interface is perturbed as depicted in Fig. 1. When the rapid repetitive triangular potential sweeps (II) reach the anodic potential limit corresponding to the formation of an oxygen monolayer and the 
cathodic potential limit is related to an intermediate surface coverage degree by the oxygen-containing species, the final triangular potential sweep (III), run at low sweep rate covering the whole potential range, shows the occurrence of two well distinguished cathodic electrodesorption current peaks related to the oxygencontaining species. The total charge of these current peaks is either practically the same as that of the cathodic charge involved in the first slow triangular potential excursion (I) or just slightly larger. The charge ratio of the two cathodic current peaks depends on the cathodic potential limit set for the cyclic perturbation (II), that is, on the portion of uncovered surface reached at $E_{\mathrm{c}}$ during each cycle and on the time the cyclic perturbation lasts.

Neglecting any double layer change occurring during the cyclic perturbation, the fact that the oxygen-containing surface species electrodesorbs at higher cathodic potentials can be interpreted as a sort of dynamic ageing of the surface species. The dynamic ageing of the surface is definitely more efficient than the ageing produced by potentiostatting the interface at $E_{\lambda}$ during different times (Fig. 2b). During the latter only a cathodic current peak is observed which is shifted ca. $0.120 \mathrm{~V}$ towards cathodic potentials with respect to the one initially recorded without surface ageing.

The chosen values of $E_{\mathbf{c}}$ and $E_{\lambda}$ for the potential perturbation (II) allow us to attain a partially clean electrode surface periodically during cycling. During each partial cathodic scan it is reasonable to assume that the more reactive species are those which are initially removed. When this occurs, a reaccommodation of the rest of the covered surface takes place. This change corresponds to a structure change of the surface species without any appreciable change of its oxidation state. The more stable species can therefore be produced either by an induced ageing of the dynamic perturbation on the covered electrode surface or directly by electrosorption of the stable species on the uncovered sites produced during the cyclic potential scanning. The first possibility formally corresponds to a reaction such as

$\mathrm{Pt}_{x}(\mathrm{O})_{y} \rightarrow \mathrm{Pt}_{x} \mathrm{O}_{y}$

where the parentheses indicate a loosely bound oxygen species on platinum and the reaction is favoured when $x>y$. The limit corresponds to the oxygen-containing monolayer, namely, $x=y$. Species $\mathrm{Pt}_{x} \mathrm{O}_{y}$ are electrodesorbed with more difficulty than species $\mathrm{Pt}_{x}(\mathrm{O})_{y}$.

The alternative reaction pathway can be expressed:

$$
\begin{aligned}
& \mathrm{Pt}_{(1-x)}+z \mathrm{H}_{2} \mathrm{O} \rightarrow \mathrm{Pt}_{(1-x)}(\mathrm{OH})_{z}+z \mathrm{H}^{+}+z e \\
& \mathrm{Pt}_{(1-x)}(\mathrm{OH})_{z} \rightarrow \mathrm{Pt}_{(1-x)} \mathrm{O}_{z}+z \mathrm{H}^{+}+z e \\
& \text { or } \\
& \mathrm{Pt}_{(1-x)}(\mathrm{OH})_{z} \rightarrow \mathrm{Pt}_{(1-x)} \mathrm{O}_{(z / 2)}+z / 2 \mathrm{H}_{2} \mathrm{O}
\end{aligned}
$$

Steps (2a) to (2c) should be considered only as possible overall reactions at the bare electrode surface. Under the monolayer conditions $(1-x)=z / 2$, and at intermediate coverages, $(1-x)>z / 2$. Either $\mathrm{Pt}_{x} \mathrm{O}_{y}$ or $\mathrm{Pt}_{(1-x)} \mathrm{O}_{z / 2}$ represent the more stable surface species. 


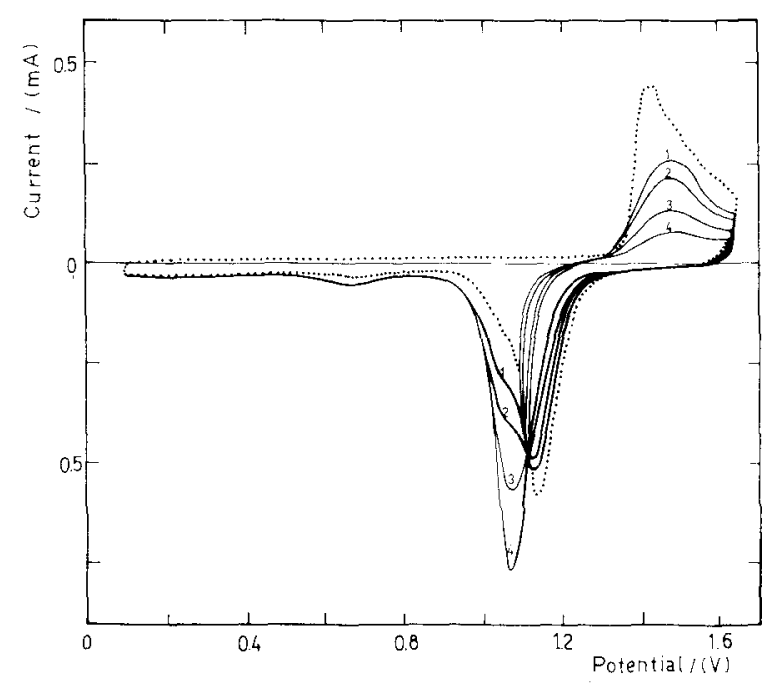

Fig. 3. $E / I$ displays resulting with the potential perturbations as indicated in Fig. 1 with the $\mathrm{Au} / 0.1 \mathrm{M} \mathrm{H}_{2} \mathrm{SO}_{4}$ system at $25^{\circ} \mathrm{C}$. Electrode area $0.5 \mathrm{~cm}^{2} . E_{\mathrm{i}}=0.09 \mathrm{~V} ; E_{\lambda}=1.65 \mathrm{~V} ; v_{\mathrm{a}}=v_{\mathrm{c}}$ $=0.4 \mathrm{~V}^{-1} \mathrm{~s} ; v_{\mathrm{a}}^{\prime}=v_{\mathrm{c}}^{\prime}=40 \mathrm{~V}^{-1} \mathrm{~s} ; \tau=3 \mathrm{~min} ; E_{\mathrm{c}}=1.110 \mathrm{~V}$ (curve 1), $1.115 \mathrm{~V}$ (curve 2), 1.125 $\mathrm{V}$ (curve 3 ) and $1.130 \mathrm{~V}$ (curve 4 ).

The results obtained with the Pt/aqueous acid interfaces show that complete electrodesorption of the aged oxygen-containing species is only attained in so far as the cathodic potential sweep reaches to the hydrogen electrode potential or even lower. When the cathodic potential limit is more positive than the potential of the hydrogen electrode, the electroreduction of the aged surface species is quite likely to be incomplete and, moreover, the amount of charge left depends on the perturbation conditions applied to the electrochemical interface. This is evidenced for instance in the change of the baseline for the electrosorption of the hydrogen adatoms.

A dynamic ageing is also observed for the $\mathrm{Au} / 0.1 \mathrm{M} \mathrm{H}_{2} \mathrm{SO}_{4}$ interface (Fig. 3) although the corresponding shift of the cathodic current peak potential is less spectacular than that observed for the Pt/aqueous acid interfaces. The different cathodic $E / I$ profiles resulting after the fast potential sweep perturbations are straightforwardly comparable to those previously reported [3] using fast asymmetric single triangular potential sweeps involving charges smaller than that of an oxygen monolayer, the latter based upon the $\mathrm{Au}_{2} \mathrm{O}_{3}$ stoichiometry.

\section{ACKNOWLEDGEMENT}

This work is part of the research program of the Electrochemistry Division of INIFTA, sponsored by the Universidad Nacional de La Plata, the Consejo Nacional de Investigaciones Científicas y Técnicas and the Comision de Investigaciones Científicas de la Provincia de Buenos Aires.

\section{REFERENCES}

1 H. Angerstein-Kozlowska, B.E. Conway and W.B.A. Sharp, J. Electroanal. Chem., 43 (1973) 9.

2 N.R. de Tacconi, A.J. Calandra and A.J. Arvia, J. Electroanal. Chem., 51 (1974) 25.

3 C.M. Ferro, A.J. Calandra and A.J. Arvia, J. Electroanal. Chem., 59 (1975) 239.

4 J.O. Zerbino, N.R. de Tacconi, A.J. Calandra and A.J. Arvía, J. Electrochem. Soc., in press. 